\title{
Fuel Property Effects on Distributed Combustion
}

\author{
Ahmed E.E. Khalil and Ashwani K. Gupta* \\ Department of Mechanical Engineering, \\ University of Maryland, College Park, MD 20742, USA
}

Abstract

Colorless Distributed Combustion (CDC) has been shown to provide benefits on ultra-low pollutants emission, enhanced stability and thermal field uniformity. The impact of fuel type (methane, propane, and hydrogen enriched methane) on achieving distributed combustion is investigated. A mixture of nitrogen and carbon dioxide was mixed, at different temperatures, with the normal air upstream of the combustor to simulate the hot recirculated gases. Increasing the amounts of nitrogen and carbon dioxide reduced the oxygen concentration within the combustor. Distributed combustion was identified through $\mathrm{OH}^{*}$ chemiluminescence distribution across the combustor. For methane, this oxygen concentration varied between $\mathbf{1 3 . 8 \%}$ and $\mathbf{1 1 . 2 \%}$ (depending on the mixture temperature) with $85 \%$ reduction in NO emissions as compared to that without entrainment. Similar behavior was demonstrated with propane and hydrogen enriched methane, albeit at a lower oxygen concentration (13.7\%-11.6\% and $12.2 \%-10.5 \%)$, to result in $94 \%$ and $92 \%$ reduction in NO emission, respectively. The mixed gases temperature was varied between $300 \mathrm{~K}$ and 750K. Experimental data using a variety of fuels showed NO emissions of 1 PPM or less. Analysis and extrapolation of obtained data suggest that distributed combustion can be achieved at an oxygen concentration of $9.5 \%$ for hot reactive entrained gases having a temperature of $1800 \mathrm{~K}$. This value may be used as a guideline to achieve distributed combustion with ultra-low emission.

Keywords: Fuel flexibility, Colorless distributed combustion (CDC), Ultra-low $\mathrm{NO}_{\mathrm{x}}$ and $\mathrm{CO}$ emission, High intensity combustion.

\footnotetext{
* Corresponding author: Tel.: +1 301405 5276; Fax: +1 3013149477.

E-mail address: akgupta@umd.edu (A. K. Gupta).
} 


\section{Introduction}

The increased energy concerns in terms of energy supply and energy impact on the environment have motivated energy and combustion researchers to look into novel methods to furnish our energy needs in a sustainable way with minimal impact on the environment. Combustion engineers have focused their

5 research efforts on developing new techniques that minimize pollutants emission (such as, nitrogen oxides, carbon monoxide, unburned hydrocarbon, and soot), while maintaining high conversion (combustion) efficiency. Other important performance elements include alleviation of combustion instabilities, enhanced thermal field uniformity (pattern factor) and reduced combustion noise from the combustor. To this end, multiple combustion technologies have emerged that address the above concerns.

10 Amongst the most promising technologies are colorless distributed combustion (CDC) [1-3]. Other technologies of flameless oxidation (FLOX) $[4,5]$ and moderate or intense low-oxygen dilution (MILD) [6] have also emerged. Colorless distributed combustion (CDC) has presented itself as a new combustion method of high intensity combustion that offers ultra-low emission, high combustion efficiency, high combustion stability, and enhanced thermal field uniformity. These features are suitable in gas turbine

15 combustion applications. CDC shares some of the same principles of high temperature air combustion (HiTAC) that has demonstrated ultra-low emissions, uniform thermal field, and significant energy gains for atmospheric pressure furnace applications [7]. In HiTAC, low oxygen concentration air, preheated to high temperatures, is used for combustion. The temperature of combustion gases in the furnace is about $50-100^{\circ} \mathrm{C}$ higher than that of the preheated low oxygen concentration fuel-air just prior to ignition. The

20 low oxygen concentration in the incoming combustion (only about 2 to $5 \%$ by volume) can be achieved, among other methods, through the internal recirculation of combustion gases, which also increases the air temperature [7]. In CDC, decrease in oxygen concentration and increase in temperature of the fresh mixture stream is achieved through internal entrainment of hot reactive species from within the combustor. This entrainment and the subsequent adequate mixing prior to ignition are critical components

25 to achieve distributed reactions. Distributed reactions are characterized by a lower reaction rate over the 
entire volume of the combustor as opposed to the concentrated flame front characterized by high reaction rates and presence of local hot spots, to result in the same fuel consumption with lower temperature rise in the combustor. This low reaction rate is achieved through lowering the oxygen concentration of the reactants, and maintained by the increase in temperature of the reactants (both of which can be achieved

5 through entrainment of hot reactive gases). The distributed combustion regime not only avoids the formation of thin reaction zone but also the hot-spots in the flame that helps to mitigate thermal NOx formation and emission from the Zeldovich thermal mechanism [8]. The benefits of distributed combustion have been demonstrated using a variety of geometries [1-3], temperature and pressures [2, 9], and injection methods $[10,11]$.

10 For all the aforementioned investigations, increased entrainment of hot reactive gases from within the combustor decreased emissions and enhanced thermal field uniformity in the combustion chamber; however, critical questions concerning the minimum required amount of entrainment has not been addressed. This critical entrainment amount was investigated in a swirl burner with focus on determining the oxygen concentration at which distributed reaction occurs [12]. This work showed that distributed

15 reaction occurs at an oxygen concentration of about $14.5 \%$ with the reactants introduced at room temperature. For that investigation, methane was used as the fuel [12]. The investigation outlined that the reduction in emission is because of the oxygen concentration reduction rather than dilution of the gases. This was further confirmed by performing experiments under no dilution, air dilution (lower equivalence ratio) and $\mathrm{N}_{2}-\mathrm{CO}_{2}$ dilution (lower oxygen concentration) conditions. Reynold's number was kept constant

20 to eliminate velocity change effects. Lowering oxygen concentration demonstrated lower emission as compared to adding more air. In addition, distributed combustion was only evident in the lower oxygen concentration case while air dilution showed a consistent swirl structure [13]. In this paper, the impact of fuel type on the conditions at which distributed combustion zone is achieved is investigated. If the fuel type has minimal impact on distributed combustion conditions requirement, then one can design the 25 combustor to achieve a certain entrainment amount that satisfies these requirements leading to a fuel flexible distributed combustion operation along with all its demonstrated benefits. The examined fuels are 
methane, propane, and hydrogen enriched methane. Methane is the main component of natural gas which is gaining significant attention for clean energy production (as compared to other fossil fuels) with the added discoveries of shale gas. Propane was chosen as a representative of heavier hydrocarbons with potential development for liquid fuels. In addition, propane is a key component of liquefied petroleum

5 gas, which is being used for energy applications. Methane enrichment with hydrogen allows for stable combustion at ultra-lean conditions, minimize pollutants emission, including thermal $\mathrm{NO}_{\mathrm{x}}, \mathrm{CO}$ and $\mathrm{UHC}$ with relevance to lean operation of gas turbines.

\section{Fuels Examined and Their Properties}

Methane is the main component of natural gas ( $90 \%$ or more) which is heavily used in stationary gas turbines for electricity and power generation. The use of natural gas has been fostered by its availability through recent additional discoveries and vast amounts of shale gas reserves. Natural gas also provides the benefit of emitting less carbon dioxide per kilowatt hour of electricity as compared to other fuels

15 (almost half that of coal, $1200 \mathrm{lb} / \mathrm{MW} . \mathrm{hr}$ for natural gas versus $2100 \mathrm{lb} / \mathrm{MW} . \mathrm{hr}$ for Coal [14]). Natural gas also emits almost no heavy metal oxides as opposed to coal. All this led to the surge in natural gas use for electricity and power generation. The combustion of methane has been extensively studied. The global reaction rate for methane-air combustion is expressed as a function of temperature $(\mathrm{T})$, methane concentration $\left(\mathrm{CH}_{4}\right)$, and oxygen concentration $\left(\mathrm{O}_{2}\right)[15]$ :

20

$$
R=10^{A 1} \times\left[\mathrm{CH}_{4}\right]^{B 1} \times\left[\mathrm{O}_{2}\right]^{B 1} \times \operatorname{Exp}[D 1 / T]
$$

where the constants A1 varied between 8.48 and 11.7, B1 varied between -0.3 and $1, \mathrm{C} 1$ varied between 0.8 and 1.3, and D1 varied between -12019 and -24358, all having the units of kmoles/cubic meters, seconds and Kelvin. Nicol et al. gave a summary of these constants and their values were based on the work of different investigators [15]. 


\subsection{Propane}

Propane is considered to be the simplest hydrocarbon whose combustion characteristics are closer to the heavier and more complex hydrocarbon fuels [16]. Consequently, propane can be used as an indicator for heavier hydrocarbons behavior in the combustor. In addition, propane is used in various applications 5 as liquid petroleum gas (LPG) in domestic, industrial and transportation sectors.

\subsection{Hydrogen Enriched Methane}

Hydrogen enriched methane has shown considerable promise for ultra-lean premixed combustion for low emissions of $\mathrm{NO}_{\mathrm{x}}$. This is attributed to the lower overall equivalence ratio at which the flame can be sustained, resulting in lower temperatures in the combustion zone. However, ultra-lean flames are susceptible to local flame extinction and quenching, leading to undesirable flame characteristics, such as, flame quenching, poor combustion efficiency and acoustic combustion instabilities. The enhanced lean flame stability allows stable ultra-lean combustion without any adverse effect on increased emissions of $\mathrm{CO}$, UHC and soot. Even though the addition of hydrogen may increase $\mathrm{NO}_{\mathrm{x}}$ emission due to higher

15 flame temperature, this can be offset by the ability to burn at an overall leaner mixture [17-18] so that lower thermal $\mathrm{NO}_{\mathrm{x}}$ is produced. Previous studies described the influence of hydrogen addition on flame stability and flame speed under fuel-lean condition in a swirl-stabilized flame [19]. The lean stability limit was extended significantly with the addition of hydrogen to hydrocarbon fuel in a combustor. Hydrogen enrichment to $\mathrm{CDC}$ combustors has shown to increase the operational range of the combustor under

20 normal inlet air temperature with a minimal increase in emissions [20-21].

\subsection{Fuel Properties:}

\subsubsection{Adiabatic Flame Temperature}

Each of three fuels examined herein has its characteristic flame speed and adiabatic flame temperature, 25 which will affect the combustion characteristics, including flame stability and pollutants emission. 
Adiabatic flame temperature for different fuels used has been calculated using NASA Chemical Equilibrium with Applications software. Figure 1 summarizes the calculated adiabatic flame temperatures for the fuels used. Of the three fuels, methane have the lowest adiabatic flame temperature, while propane and hydrogen enriched methane are close to each other. This difference is expected to affect NO emission

5 as well as flammability limits for lean operation and excess entrainment.

\subsubsection{Laminar Flame Speed}

Different researchers have measured the laminar flame speed of the examined fuels. Details on the 10 techniques used and their equivalence can be found in references [22, 23]. Figure 2 shows the laminar flame speed for these fuels. Hydrogen enriched methane (8\% hydrogen by mass) is translated to $40 \% \mathrm{H}_{2}-$ $60 \% \mathrm{CH}_{4}$ by volume. The laminar flame speed changes significantly between methane at the low end and hydrogen enriched methane at the high end. Though the combustion is essentially turbulent under CDC conditions, however, the flame speeds are expected to scale similarly. The high flame speed encountered

15 with hydrogen-enriched methane might result in flashback and combustion instabilities. In addition, these flame speeds are expected to be impacted by excess entrainment and dilution.

\section{Experimental Facility}

The experiments were performed using a swirl burner fueled with the three different fuels. Details of

20 this swirl burner can be found elsewhere [24]. To simulate product gas recirculation and lower oxygen concentration in the mixture prior to ignition, different amounts of $\mathrm{N}_{2}-\mathrm{CO}_{2}$ mixture were added to the air upstream of the burner. Air and nitrogen flow rates were controlled by laminar flow controllers with an accuracy of $\pm 0.8 \%$ of reading $\pm 0.2 \%$ of full scale leading to an overall accuracy of about $1.5 \%$ of the reading. Methane and carbon dioxide flow rates were controlled through a gravimetric flow controller

25 with an accuracy of $1.5 \%$ of full scale. Fuel was injected at the center of the swirler in a non-premixed configuration. 
Detailed investigations on the overall emissions from the combustor as well as visible emissions have been performed for the various experimental conditions. Pollutants (NO and $\mathrm{CO}$ ) were measured using a Horiba PG-250 gas analyzer with an accuracy of $\pm 1 \%$ of full scale. The concentration of NO was also measured using a $\mathrm{NO}-\mathrm{NO}_{\mathrm{x}}$ chemiluminescence method with an accuracy of $\pm 0.5 \mathrm{PPM}$; CO concentration

5 was measured using the non-dispersive infrared method with an accuracy of \pm 1 PPM, and $\mathrm{O}_{2}$ concentration (used to correct the $\mathrm{NO}$ and $\mathrm{CO}$ emission at standard $15 \%$ oxygen concentration) was measured using galvanic cell method with an accuracy of $\pm 0.1 \%$. During a single experiment, measurements were repeated at least three times for each configuration and the uncertainty was estimated to be about $\pm 0.5 \mathrm{PPM}$ for NO, and $\pm 10 \%$ for $\mathrm{CO}$ emission. The experiments were repeated at least three 10 times to ensure good repeatability of the experimental data.

For imaging the $\mathrm{OH}^{*}$ chemiluminescent intensity distribution, an ICCD camera coupled to a narrow band filter, centered at wavelength $307 \mathrm{~nm}$ wavelength, was used. A photograph of the experimental test rig is shown in Fig. 3, along with the flame under standard air combustion, where the swirl structure is dominant, and reduced oxygen concentration combustion showing near distributed combustion with less

15 visible emission. For both cases, the flames were confined in the quarts tube having an internal diameter of 3 inches and length of 12 inches. The swirl burner details can be found elsewhere [24]. Thermocouples were fitted along the reactor walls to confirm the existence of reaction zone at low oxygen concentration as the flame was invisible with almost no combustion noise.

The entrained gases consisted of nitrogen, carbon dioxide, water vapor, and excess oxygen (depending 20 on the stoichiometry of the reaction). To simulate the impact of entrainment of reactive gases on the combustion process, nitrogen and carbon dioxide were introduced with the fresh mixture, with a focus to determine oxygen concentration at which distributed combustion can be fostered. Based on this required oxygen concentration and the combustor design equivalence ratio, a hot reactive gas entrainment ratio can be determined (taking into account the amount of excess oxygen entrained).

25 Nitrogen and carbon dioxide were selected as they form the majority of the product gases from a combustor. They were mixed in a ratio of $90 \% \mathrm{~N}_{2}, 10 \% \mathrm{CO}_{2}$ by volume simulating product gases near 
stoichiometric conditions. Though this ratio changes as the equivalence ratio becomes leaner, the diluting gases mixture (90\%-10\%) was kept constant for all the investigations reported here. This deviation from the actual gases will have minimal impact on the results as nitrogen and carbon dioxide behave similarly in flames. Laminar flame speed and flame temperature for methane-air flames diluted with nitrogen

5 and/or carbon dioxide have shown to exhibit similar behavior $[25,26]$. Diluting the reactants with a nitrogen-carbon dioxide-water vapor mixture also resulted in similar behavior to that of nitrogen [27].

The dilution gases were supplied upstream of the combustor at different temperatures and amounts to evaluate the role of the mixture temperature prior to ignition on emissions and flame stabilization for the different fuels examined here.

10

\section{Experimental Conditions}

The experimental investigations reported here were aimed at examining the $\mathrm{NO}$ and $\mathrm{CO}$ emission as well as $\mathrm{OH}^{*}$ chemiluminescence intensity as affected by oxygen concentration prior to ignition. Oxygen concentration was varied through supplying different amount of $\mathrm{N}_{2}-\mathrm{CO}_{2}$ mixture (90\%-10\% by volume).

15 First, experiments were performed under various equivalence ratios with different dilution amounts. Afterwards, the $\mathrm{N}_{2}-\mathrm{CO}_{2}$ mixture temperature was varied to outline the impact of dilution temperature on emissions and flame stability.

Table 1 summarizes the conditions reported here along with the variables manipulated for each case. For each heat load, the fuel flow rate was kept constant while the air flow rate was changed to vary the 20 equivalence ratio. For every equivalence ratio, air and fuel flow rates were kept constant while the amount of $\mathrm{N}_{2}-\mathrm{CO}_{2}$ mixture was increased to lower the oxygen concentration in the mixture prior to ignition. For all the experiments reported here, the head load was kept constant at $3.25 \mathrm{KW}$ and a heat release intensity of $2.4 \mathrm{MW} / \mathrm{m}^{3}-\mathrm{atm}$ 


\section{Results and Discussion}

\subsection{Methane Fuel}

Experiments first focused on methane flame behavior and structure with increased amounts of diluents $\left(\mathrm{N}_{2}\right.$ and $\mathrm{CO}_{2}$, simulating entrained hot gases). This increase in diluents amount led to a decrease in

5 oxygen concentration in the fresh mixture. The experiments were performed at diluents temperature ranging from $300 \mathrm{~K}$ to $750 \mathrm{~K}$. The global flame structure was captured using $\mathrm{OH}^{*}$ chemiluminescence and the results obtained are shown in Fig. 4.

As the oxygen concentration was reduced, the reaction structure changes from that associated with swirl combustion, where the swirl lobes are present, to a more uniform $\mathrm{OH}^{*}$ intensity distribution across

10 the entire reaction zone. This phenomena has been previously observed for methane at 300 and $600 \mathrm{~K}$ [12] which was further complemented by $\mathrm{OH}^{*}$ chemiluminescence data at $450 \mathrm{~K}$ and $750 \mathrm{~K}$. As the diluents temperature increases, the oxygen concentration at which the combustor transitions to distributed combustion decreases. At $300 \mathrm{~K}$, the reaction transitioned at an oxygen concentration of $\sim 13.8 \%$. This concentration decreased to $12.4 \%, 11.8 \%$, and $11.2 \%$ at temperature of $450 \mathrm{~K}, 600 \mathrm{~K}$, and $750 \mathrm{~K}$,

15 respectively. The transition to distributed combustion is identified by the disappearance of concentrated zones of higher chemiluminescence signal to uniformly distributed $\mathrm{OH}^{*}$ distribution.

The pollutants emission was also recorded for this experiment. Figure 5 shows the respective NO emission. As the diluents amount was increased (decreasing the oxygen concentration), the NO emission sharply decreased. For instance, at 300K, NO emissions decreased from 13.3 PPM down to 2.2 PPM at

20 oxygen concentration of $13.8 \%$. Increase in the diluents temperature increased NO emission at a given oxygen concentration. This is attributed to the increase in reaction temperature and adiabatic flame temperature as a result of the increased fresh mixture temperature. However, increase in the diluents temperature stabilized the flame at lower oxygen concentration to result in further reduction in NO emission. For the examined temperatures, NO emissions were about 2 PPM at the transition point to near 25 distributed combustion with NO concentration of 1.88, 1.76, 1.56 and 2.07 PPM, at oxygen concentration 
of $13.8 \%, 12.4 \%, 11.8 \%, 11.2 \%$ and temperatures of $300,450,600$, and $750 \mathrm{~K}$, respectively, to result in about $83 \%$ reduction in $\mathrm{NO}$ emission as compared to normal air combustion.

In terms of $\mathrm{CO}$ emissions, there was minimal change with oxygen concentration or diluents temperature. However, when the oxygen concentration was significantly reduced, the flame approached

5 its flammability limit and resulted in an unstable behavior that led to a rise in CO emission as shown in Fig. 6. However, emission at the transition point to distributed combustion was about $\sim 6$ PPM for the different temperatures examined here.

The experiments were also repeated at a lower equivalence ratio of $0.7 . \mathrm{OH}^{*}$ chemiluminescence demonstrated similar trend, where the reaction transition to distributed combustion upon decrease in the

10 oxygen concentration. This in return reflected on NO emission with NO value down to 1 PPM at the transition point with $\mathrm{CO}$ emission of $3 \mathrm{PPM}$.

\subsection{Propane Fuel}

Experiments with propane fuel followed the same procedure as that with methane. The experiments

15 were performed at diluents temperature ranging from $300 \mathrm{~K}$ to $750 \mathrm{~K}$. The flame structure was captured using $\mathrm{OH}^{*}$ chemiluminescence and the results are shown in Fig. 7.

Similar to methane, as the oxygen concentration was reduced, the reaction structure changed from that associated with swirl combustion, where the swirl lobes are present, to a more uniform $\mathrm{OH}^{*}$ intensity distribution across the entire reaction zone. The transition to distributed combustion was found to occur at

20 oxygen concentrations of $13.7 \%, 12.9 \%, 12.2 \%$ and $11.6 \%$ at temperatures of $300,450,600$ and $750 \mathrm{~K}$, respectively. For temperatures of $300 \mathrm{~K}$ and $450 \mathrm{~K}$, these value are lower than that of methane which can be related to the stronger combustion associated with propane as evidenced by the higher chemiluminescence signal (16000 a.u. as compared to 10000 for methane). However, this difference was minimal at higher diluents temperature, where the difference was only about $0.2 \%$. Moreover, propane 25 enabled stable combustion at lower oxygen concentration. The flame was stable until oxygen 
concentrations of $12.25 \%$ at $300 \mathrm{~K}$ as opposed to $13.8 \%$ for methane. This trend was also demonstrated at higher diluents temperature.

Figure 8 shows the NO emission with propane fuel for the different oxygen concentration and diluents' temperature. For normal air combustion (no diluents), NO emission from propane fuel was

5 higher than that of methane (17.6 PPM vs. 13.3 PPM), which is consistent with previously reported experiments [28]. However, upon transition to distributed combustion, NO emissions were significantly lower. For the transition to distributed combustion, NO emissions were 1, 0.9, 0.9, and 0.75 PPM for diluents temperature of $300,450,600$ and $750 \mathrm{~K}$, respectively. This amounts to about $94 \%$ reduction in NO emission as compared to normal air combustion.

10 There was minimal change in $\mathrm{CO}$ emission with oxygen concentration or diluents temperature. Experimental results showed a sharp increase in $\mathrm{CO}$ emission when the oxygen concentration was significantly reduced. At these conditions, the flame approached its flammability limit and resulted in an unstable behavior that led to a rise in $\mathrm{CO}$ emission as shown in Fig. 9. However, emission at the transition to distributed combustion was about $\sim 3$ PPM for the different temperatures examined here.

15 Experiments performed at a lower equivalence ratio of 0.7 demonstrated similar trends in terms of $\mathrm{OH}^{*}$ chemiluminescence and emissions. NO emission of less than 1 PPM was recorded along with CO emission of $3 \mathrm{PPM}$ at the transition points (low oxygen concentration) to distributed combustion condition.

\subsection{Hydrogen Enriched Methane Fuel}

Experiments on hydrogen-enriched methane followed the same procedure as that with methane and propane. The experiments were performed at diluents temperature ranging from $300 \mathrm{~K}$ to $750 \mathrm{~K}$. The main difference between hydrogen enriched methane and the other two fuels examined is the extended operational limit, where the combustion was found to be stable at lower oxygen concentration. The flame structure was captured using $\mathrm{OH}^{*}$ chemiluminescence and is shown in Fig. 10. 
The flame structure resembled that of methane and propane. As the oxygen concentration was reduced, the reaction structure changed from that associated with swirl combustion, where the swirl lobes are present, to a more uniform $\mathrm{OH}^{*}$ intensity across the entire reaction zone. The transition to distributed combustion was found to occur at oxygen concentrations of $12.19 \%, 11.59 \%, 11.03 \%$ and $10.54 \%$ at 5 respective temperatures of 300,450,600 and 750K, respectively. These values are lower than those from methane or propane fuels experiments. This can be attributed to the higher flame speed of hydrogen and the added flame stability due to the hydrogen enrichment. This excess speed and added stability prevented the flame from transitioning to distributed conditions unless the oxygen concentration was further reduced as compared to the values obtained for methane or propane fuels. In addition, the chemiluminescence

10 signal was higher (17000 a.u. as compared to 10000 for methane and 16000 for propane). However, this difference was minimal at higher diluents temperature. In terms of extended operation stability, hydrogen enriched methane was found to be stable until oxygen concentration of $10.54 \%$ at $300 \mathrm{~K}$; this value is lower than that for methane (13.8\%) and propane $(12.25 \%)$. This trend was also demonstrated at higher diluents temperature.

15 The NO and $\mathrm{CO}$ emissions resulting from hydrogen enriched methane combustion were recorded. Figure 11 shows the NO emission for the different oxygen concentrations and diluents temperatures. For normal air combustion (no diluents), hydrogen enriched methane NO emission was higher than that from the other two fuels (23.8 PPM opposed to 17.6 PPM and 13.3 PPM). When the combustor transitioned to distributed combustion, NO emissions were significantly lower. For distributed combustion, NO 20 emissions were $1.95,1.9,1.9$, and 2 PPM for diluents temperature of 300, 450, 600 and $750 \mathrm{~K}$, respectively. This amounts to about $92 \%$ reduction in NO emissions as compared to normal air combustion.

For $\mathrm{CO}$ emission, there was minimal change with oxygen concentration or diluents temperature. Experimental results showed a sharp decrease in $\mathrm{CO}$ emissions with the onset of dilution. On the other

25 hand, $\mathrm{CO}$ emission increased significantly when the oxygen concentration reached its lower bound. At these conditions, the flame approached its flammability limit and resulted in an unstable behavior that led 
to a rise in $\mathrm{CO}$ emissions, see Fig. 12. However, emission at the transition point to distributed combustion was about $\sim 12$ PPM for the different temperatures examined here.

Experiments performed at a lower equivalence ratio of 0.7 demonstrated similar trends in terms of $\mathrm{OH}^{*}$ chemiluminescence and emissions. NO emissions of less than 1 PPM were recorded along with CO

5 emission of 2 PPM at the transition point (oxygen concentration) to distributed combustion.

\subsection{Impact of Oxygen Concentration on Emission}

The data in figures 5,8 and 11 can be combined to demonstrate the impact of oxygen concentration on emission for the different fuels. The combined data is shown in Fig. 13. Since the temperature impact is

10 minimal (compared to the oxygen concentration impact), one can obtain a relationship for NO emission as a function of oxygen concentration for the different fuels examined. A third degree polynomial fit was chosen for the curve fitting as a second degree polynomial fit demonstrated emission increase for the lower oxygen concentrations which contradicts with the experimental measurements and data trend. The curve fitting results along with the regression coefficient for each curve is shown in Fig. 13. The first 15 equation is for methane, followed by propane then hydrogen enriched methane at the bottom, where y represents the $\mathrm{NO}$ emission and $\mathrm{x}$ represents the oxygen concentration.

Analyzing the data for experiments at an equivalence ratio of 0.7 resulted in similar trend. Figure 14 shows the emissions and the relative relations (top methane, middle propane, and bottom hydrogen enriched methane).

20 Furthermore, if the data for the three fuels is combined, a single relation can be obtained to predict the corrected NO emission for different oxygen concentrations in the oxidizer. The relation for an equivalence ratio of 0.9 takes the following form:

$$
N O=0.189 \times\left[O_{2}\right]^{3}-0.6588 \times\left[O_{2}\right]^{2}+7.7511 \times\left[O_{2}\right]-29.13
$$

where NO is the NO emission in PPM, corrected to $15 \% \mathrm{O}_{2}$ in the exhaust, and $\left[\mathrm{O}_{2}\right]$ is the oxygen

25 concentration in the mixture prior to ignition. This relation has a regression coefficient of 0.89 , which is 
lower than that of the fuel specific relations (shown in Fig. 13), due to the differences in emission between the fuels, especially for normal air combustion, yet it is a useful relation to predict NO emission for different oxygen concentration and fuels examined herein. This relation can also be extended to cover other fuels/fuel mixtures that have similar properties to the fuels reported here.

\subsection{Distributed Combustion under Realistic Conditions}

For all the experiments performed here, the diluents' temperatures varied up to $750 \mathrm{~K}$. Realistically, for internal entrainment of hot reactive gases from within the combustor, this temperature shall be in the range of $1800 \mathrm{~K}$. Though experiments were not performed at this temperature, one can gain useful insights

10 plotting the oxygen concentration at which the reaction transitions to distributed combustion against the diluents temperature. Figure 15 shows these transition points for the different fuels examined.

If the data points are to be combined, an expression relating the oxygen concentration needed for distributed combustion and diluent temperature can be obtained. The resultant relation takes the following form:

$$
O_{2}=38.162 \times T^{-0.186}
$$

where $\mathrm{O}_{2}$ is the oxygen concentration at which the reaction transitions to distributed combustion (in percentage) and $\mathrm{T}$ is the diluents temperature in $\mathrm{K}$. This equation is also plotted on Fig 15 (solid black line) with $\pm 0.75 \%$ (dashed black lines). One can see that the experiments fall within these bounds except at $300 \mathrm{~K}$, where the fuel properties play an important rule. As the diluents temperature increased, these variations were minimized. Using the obtained relation, the oxygen concentration at which the reaction transitions to distributed combustion at a diluent temperature of $1800 \mathrm{~K}$ is found to be $9.5 \%$.

If we consider each fuel on its own, the equations take the following form:

$$
\begin{aligned}
& \mathrm{CH}_{4}: O_{2}=48.71 \times T^{-0.222} \\
& \mathrm{C}_{3} \mathrm{H}_{8}: O_{2}=37.892 \times T^{-0.178}
\end{aligned}
$$

$25 \quad \mathrm{H}_{2}+\mathrm{CH}_{4}: O_{2}=30.11 \times T^{-0.158}$ 
with regression coefficients of $0.9911,0.985$, and 0.9873 respectively. If these equations are to be used to predict the transition point at $1800 \mathrm{~K}$, these points will be at $9.22 \%, 9.98 \%$, and $9.2 \%$ respectively, which is not far from the global value of $9.5 \%$.

Reduction of oxygen concentration down to about $9.5 \%$ requires knowledge of the combustor operational equivalence ratio (dictating the amount of excess oxygen concentration in the entrained hot gases inside the combustor). If the combustor is operated using methane fuel at an equivalence ratio of 0.6 (with $8 \% \mathrm{O}_{2}$ measured in the combustion exhaust without dilution), achieving an oxygen concentration of $9.5 \%$ will dictate an entrainment ratio of 8.66 (i.e., the amount of hot entrained gases is equal to 8.66 of that of the fresh air intake) [29]. On the other hand, if the combustor is operated at an equivalence ratio of 0.9 (with $0.75 \% \mathrm{O}_{2}$ measured in the combustion exhaust without dilution), achieving oxygen concentration of $9.5 \%$ requires only an entrainment ratio of 2.3. Though such a high equivalence ratio traditionally results in high emissions, internal entrainment resulted in significant emission reduction as shown in Fig. 5.

The same approach can be applied to propane experiments. Achieving distributed combustion

15 will require a recirculation ratio of 13.5 at an equivalence ratio of 0.6 . If the combustor is to be operated at an equivalence ratio of 0.9 , the needed entrainment ratio will be 3.4. For hydrogen enriched methane, these values will be $5.6(\mathrm{phi}=0.6)$ and $2.5(\mathrm{phi}=0.9)$.

\section{Conclusions}

20 Distributed combustion conditions were examined for three different fuels (methane, propane, and hydrogen enriched methane) with focus on pollutants emission and transition to distributed combustion condition. $\mathrm{OH}^{*}$ chemiluminescence was used to determine the flame structure at different conditions and outline the transition to distributed combustion conditions. $\mathrm{OH}^{*}$ showed 
a significant reduction in signal intensity with oxygen concentration reduction along with the disappearance of the traditional swirl lobes associated with swirl combustion disappeared.

Results obtained with methane fuel with increase in oxygen concentration reduction in the fresh mixture, as well as diluents temperatures, demonstrated significant decrease in NO

5 emission with minimal impact on CO emission. NO emission was reduced by more than $80 \%$ and emission lower than 2 PPM was demonstrated upon transition to distributed combustion. Propane fuel demonstrated similar behavior with 94\% NO reduction (emitting only 1 PPM NO) upon flame transition to distributed combustion. Hydrogen enriched methane followed the trend 92\% reduction (1.9 PPM NO). At a lower equivalence of 0.7 , emissions as low as 1 PPM NO

10 and 3 PPM CO were demonstrated for the different fuels examined under distributed combustion condition.

The data from the different fuels and oxygen concentrations was compiled to give a global equation that can predict $\mathrm{NO}$ emission as a function of the oxygen concentration. Though there was some variation for each fuel, the global curve fit resulted in favorable agreement with the 15 data, providing a useful tool for emission prediction.

The oxygen concentration to achieve distributed combustion were somewhat different for each fuels at diluents temperature of $300 \mathrm{~K}(13.8 \%, 13.7 \%$, and $12.2 \%$ for methane, propane, and hydrogen enriched methane, respectively). This difference was minimized as the diluents temperature increased. At $750 \mathrm{~K}$, the oxygen concentrations were $11.23 \%, 11.6 \%$, and $10.5 \%$, 20 respectively.

The data on oxygen concentration at which the combustor transitions to distributed combustion can be extrapolated to predict required oxygen concentrations and recirculation ratio required under actual combustion conditions. For an entrained gas temperature of $1800 \mathrm{~K}$, the 
required oxygen concentration to achieve distributed combustion is estimated to be approximately $9.5 \%$.

The results presented here demonstrate the benefit of distributed combustion as a means to achieve ultra-low emissions with good fuel flexibility. Results showed that, distributed

5 combustion conditions can provide emissions below 2 PPM of NO. These emissions, combined with the distributed $\mathrm{OH}^{*}$ chemiluminescence images shown under distributed combustion conditions, highlights the beneficial aspects of distributed combustion conditions and its ability to handle different fuels with ultra-low emissions.

\section{Acknowledgments}

This research was supported by ONR and is gratefully acknowledged.

\section{References}

15 [1] Khalil AEE, and Gupta AK. Swirling Distributed Combustion For Clean Energy Conversion In Gas Turbine Applications. J. Applied Energy 2011;88:3685-93.

[2] Khalil AEE, and Gupta AK. Distributed Swirl Combustion for Gas Turbine Application. J. Applied Energy 2011;88:4898-907.

[3] Arghode VK, and Gupta AK. Effect of Flowfield for Colorless Distributed Combustion (CDC)

20 for Gas Turbine Combustion. J. Applied Energy 2010;78:1631-40.

[4] Wunning JA, and Wunning JG. Flameless Oxidation to Reduce Thermal NO Formation. Progr. in Energy and Combustion Science 1997;23:81-94. 
[5] Lammel O, Schutz H, Schmitz G, Luckerath R, Stohr M, Noll B, Aigner M, Hase M, Krebs W. FLOX Combustion at High Power Density and High Flame Temperature. Journal of Engineering for Gas Turbine and Power 2010;132:121503.

[6] Weber R, Smart JP, Vd Kamp W. On the (MILD) Combustion of Gaseous, Liquid, and Solid 5 Fuels in High Temperature Preheated Air. Proceedings of the Combustion Institute 2005;30:2623-29.

[7] Tsuji H, Gupta AK, Hasegawa T, Katsuki M, Kishimoto K, Morita M. High temperature air combustion: from energy conservation to pollution reduction. Boca Raton: CRC Press.;2003

[8] Correa SM. A Review of NOx Formation under Gas-Turbine Combustion Conditions. Combustion Science and Technology 1992;87:329-62.

10 [9] Khalil AEE, and Gupta AK. Impact of Pressure on High Intensity Colorless Distributed Combustion. J. Fuel 2015;143:334-342.

[10] Khalil AEE, Gupta AK, Bryden MK, Lee SC. Mixture Preparation Effects on Distributed Combustion for Gas Turbine Applications. J. Energy Resour. Technol. 2012;134(3):032201.

[11] Khalil AEE, and Gupta AK. Velocity and Turbulence Effect on Distributed Combustion for 15 Clean Gas Turbine Engines. J. Applied Energy 2014;125:1-9.

[12] Khalil AEE, and Gupta AK. Impact of Internal Entrainment on High Intensity Distributed Combustion. J. Applied Energy 2015;156:241-250.

[13] Khalil AEE, and Gupta AK. Thermal Field Investigation under Distributed Combustion Conditions. J. Applied Energy, In Press, 10.1016/j.apenergy.2015.09.058.

20 [14] http://www.eia.gov/tools/faqs/faq.cfm?id=74\&t=11

[15] Nicol DG, Malte PC, Hamer AJ, Roby RJ, Steele RC. Development of a Five-Step Global Methane Oxidation-NO Formation Mechanism for Lean-Premixed Gas Turbine Combustion. J. Eng. Gas Turbines Power, 1999;121(2):272-280

[16] Turns, S. R., 2000, An Introduction to Combustion: Concepts and Applications, 2nd Ed., 25 McGraw-Hill Book Co. 
[17] Choudhuri AR, and Gollahalli SR. Combustion Characteristics of Hydrogen-Hydrocarbon Hybrid Fuels. Int'1 J. Hydrogen Energy, 2000;25:451-462.

[18] Choudhuri AR, and Gollahalli SR. Characteristics of Hydrogen-Hydrocarbon Composite Fuel Turbulent Jet Flame. Int'1 J. Hydrogen Energy, 2003;28:445-454.

5 [19] Karbasi M, and Weirzba I. The Effect of Hydrogen Addition on the Flame Stability Limits of Methane Jet Diffusion Flames. Int'1 J. Hydrogen Energy, 1997;23:123-129.

[20] Arghode VK, and Gupta AK. Hydrogen addition effects on methane-air colorless distributed combustion flames. Int'l J. Hydrogen Energy, 2011;36:6292-6302.

[21] Khalil AEE, and Gupta AK. Hydrogen Addition Effects On High Intensity Distributed 10 Combustion. J. Applied Energy 2013;104:71-78.

[22] Vagelopoulos CM, Egolfopoulos FN, and Law CK. Further Considerations on the Determination of Laminar Flame Speeds With the Counterflow Twin Flame Technique. Proc. Comb. Inst 1994;25:13412347.

[23] Hu E, Huang Z, He J, Jin C, and Zheng J. Experimental and Numerical Study on Laminar

15 Burning Characteristics of Premixed Methane-Hydrogen-Air Flames. Int'l J. Hydrogen Energy, 2009;34:4876-4888.

[24] Kim HS, Arghode VK, Linck MB, Gupta AK. Hydrogen Addition Effects in a Confined Swirl-Stabilized Methane-Air Flame. Int'1 J. Hydrogen Energy, 2009;34(2):1054-1062.

[25] Al-Hamamre Z, Diezinger S, Talukdar P, Von Issendorff F, Trimis D. Combustion of low 20 calorific gases from landfills and waste pyrolysis using porous medium burner technology. Process Safety Environ Protect, 2006;84(B4):297-308.

[26] Stone R, Clarke A, Beckwith P. Correlations for the laminar-burning velocity of methane/diluent/air mixtures obtained in free-fall experiments. Combust Flame, 1998;114:54655. 
[27] Galmiche B, Halter F, Foucher F, Dagaut P. Effects of Dilution on Laminar Burning Velocity of Premixed Methane/Air Flames. Energy \& Fuels, 2011;25:948-954.

[28] Khalil AEE, and Gupta, AK. Fuel Flexible Distributed Combustion With Swirl For Gas Turbine Applications. J. Applied Energy, 2013;109:327-334.

5 [29] Khalil AEE, and Gupta AK. Towards Distributed Combustion for Ultra-Low Emission Using Swirling and Non-Swirling Flowfields. J. Applied Energy, 2014;121:132-139. 
Table 1. Experimental parameters

\begin{tabular}{|c|c|c|c|c|c|}
\hline & Fuel & $\begin{array}{l}\text { Content } \\
\text { (Mass) }\end{array}$ & $\begin{array}{c}\text { Equivalence } \\
\text { Ratio }\end{array}$ & $\begin{array}{c}\text { Mixture } \\
\text { Temperature } \\
\end{array}$ & $\begin{array}{c}\text { Oxygen Concentration } \\
{[\%]}\end{array}$ \\
\hline 1 & \multirow[t]{2}{*}{ Methane } & \multirow[t]{2}{*}{$100 \% \mathrm{CH}_{4}$} & 0.9 & \multirow{6}{*}{$\begin{array}{l}300 \mathrm{~K}, 450 \mathrm{~K} \\
600 \mathrm{~K}, 750 \mathrm{~K}\end{array}$} & $21-10.28 \%$ \\
\hline 2 & & & 0.7 & & $21-13.6 \%$ \\
\hline 3 & \multirow[t]{2}{*}{ Propane } & \multirow[t]{2}{*}{$100 \% \mathrm{C}_{3} \mathrm{H}_{8}$} & 0.9 & & $21-10.23 \%$ \\
\hline 4 & & & 0.7 & & $21-13.51 \%$ \\
\hline 5 & \multirow{2}{*}{$\begin{array}{c}\text { Hydrogen Enriched } \\
\text { Methane }\end{array}$} & \multirow{2}{*}{$\begin{array}{c}8 \% \mathrm{H}_{2^{-}} 92 \% \\
\mathrm{CH}_{4}\end{array}$} & 0.9 & & $21-8.92 \%$ \\
\hline 6 & & & 0.7 & & $21-9.89 \%$ \\
\hline
\end{tabular}




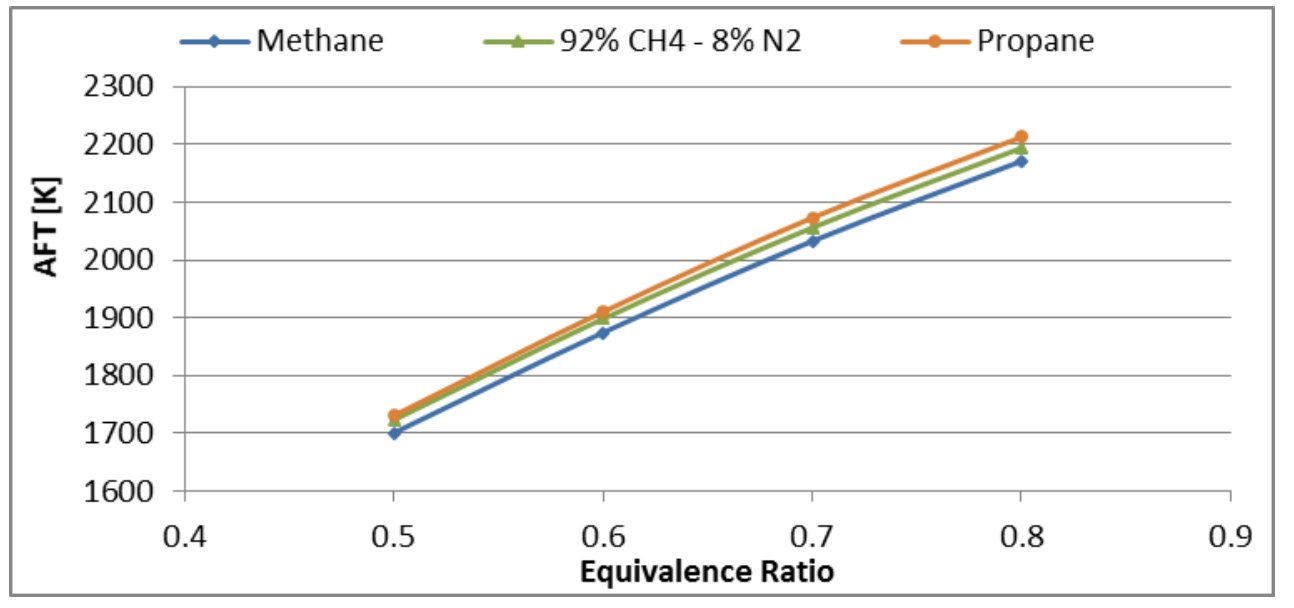

Figure 1. Calculated adiabatic flame temperature for the different fuels used

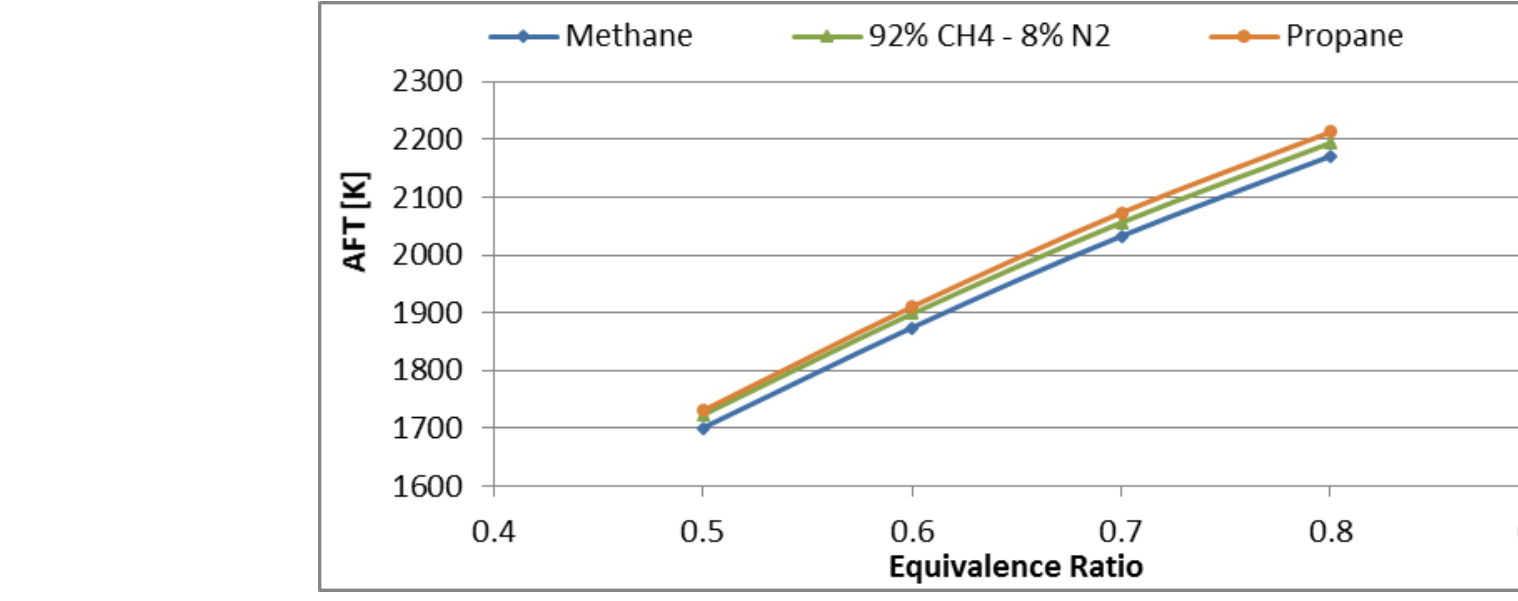

ra

(a) 


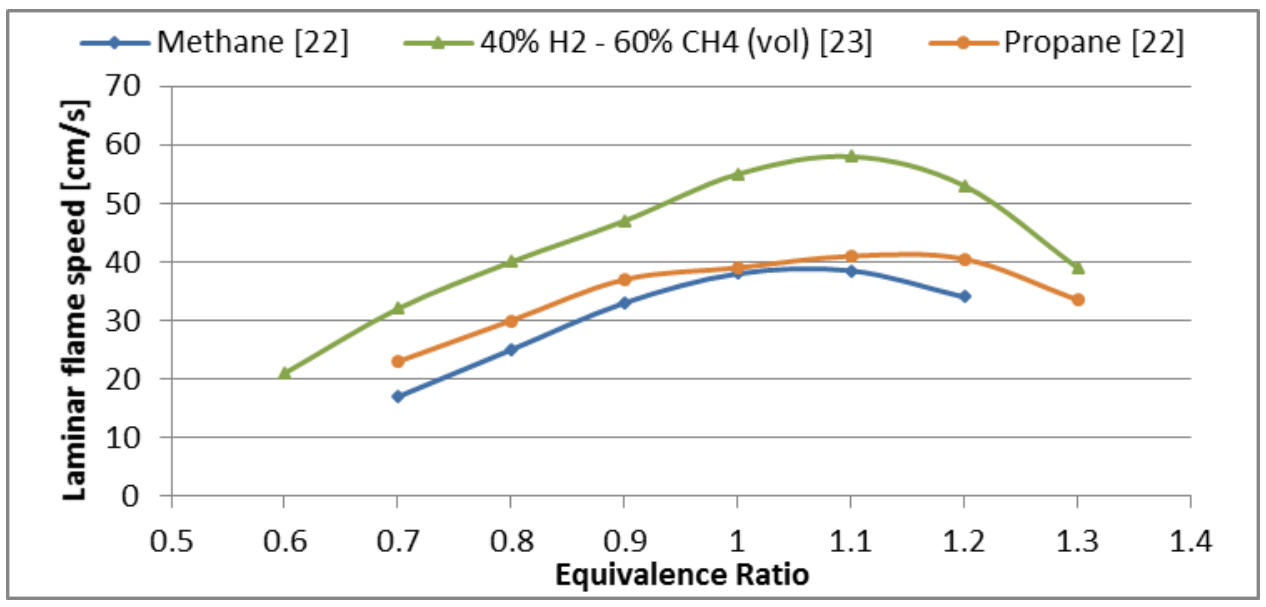

Figure 2. Laminar flame speed for the different fuels used 


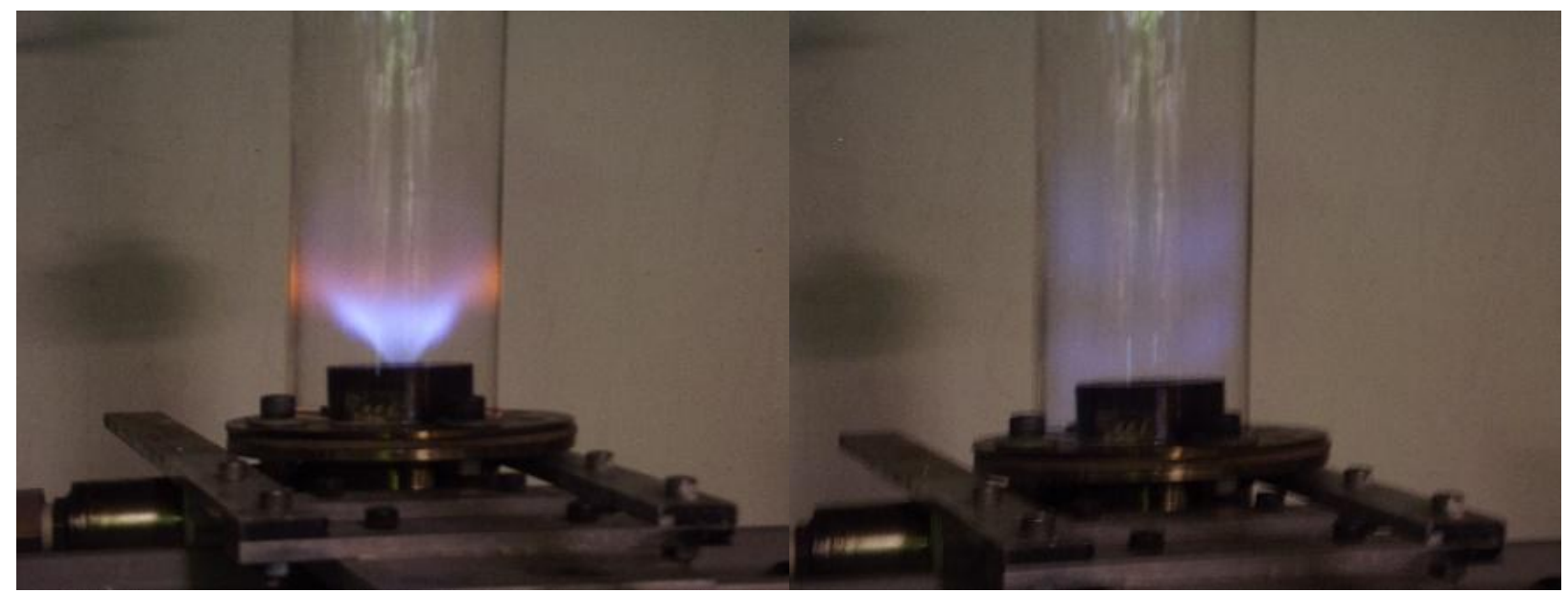

Figure 3. Experimental test rig with flame using normal air (left) and reduced oxygen concentration air (right) 


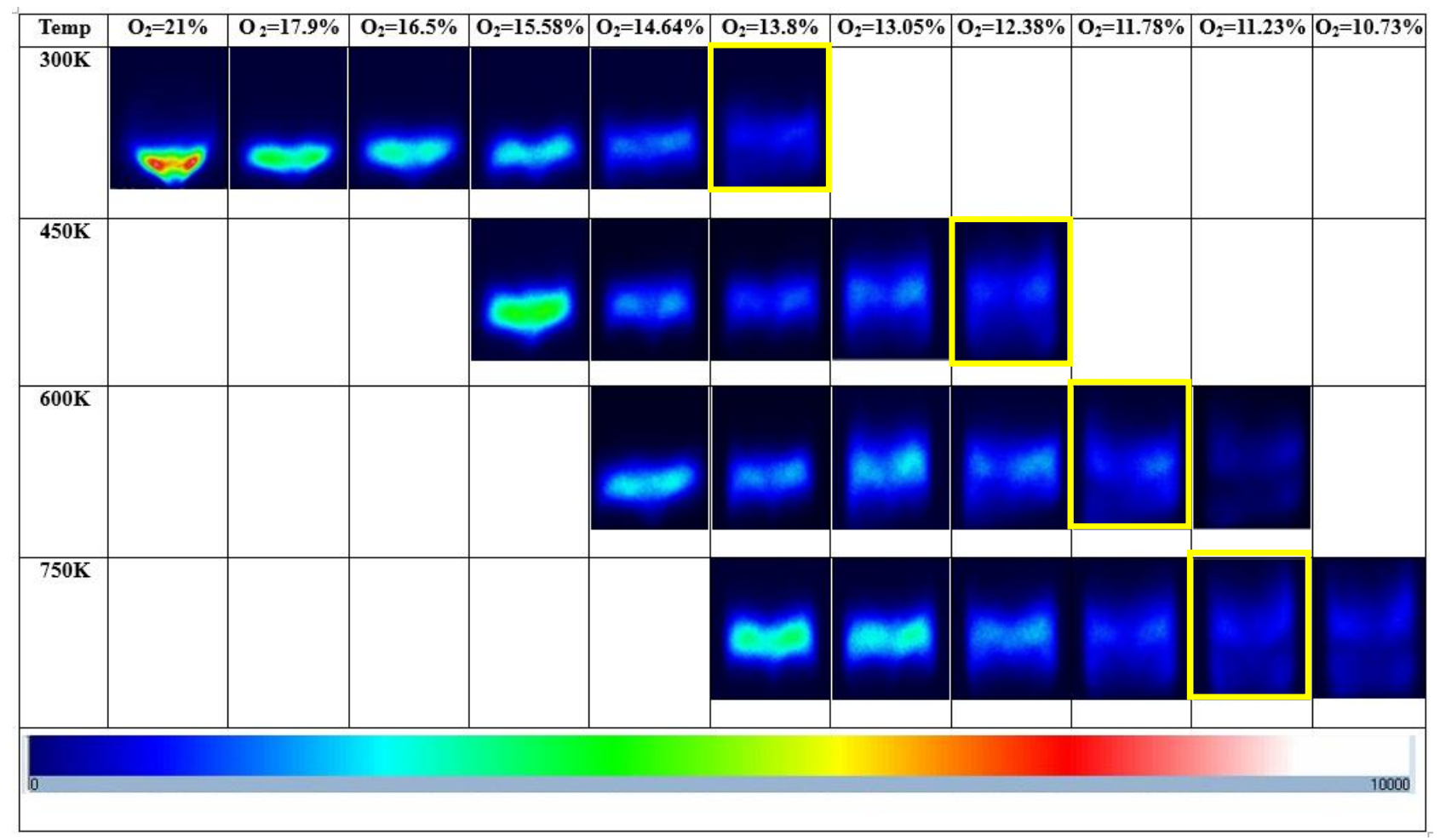

Figure 4. $\mathrm{OH} *$ Chemiluminescence for the different oxygen concentrations in reactants at temperatures ranging from 300 to $750 \mathrm{~K}$ for methane 


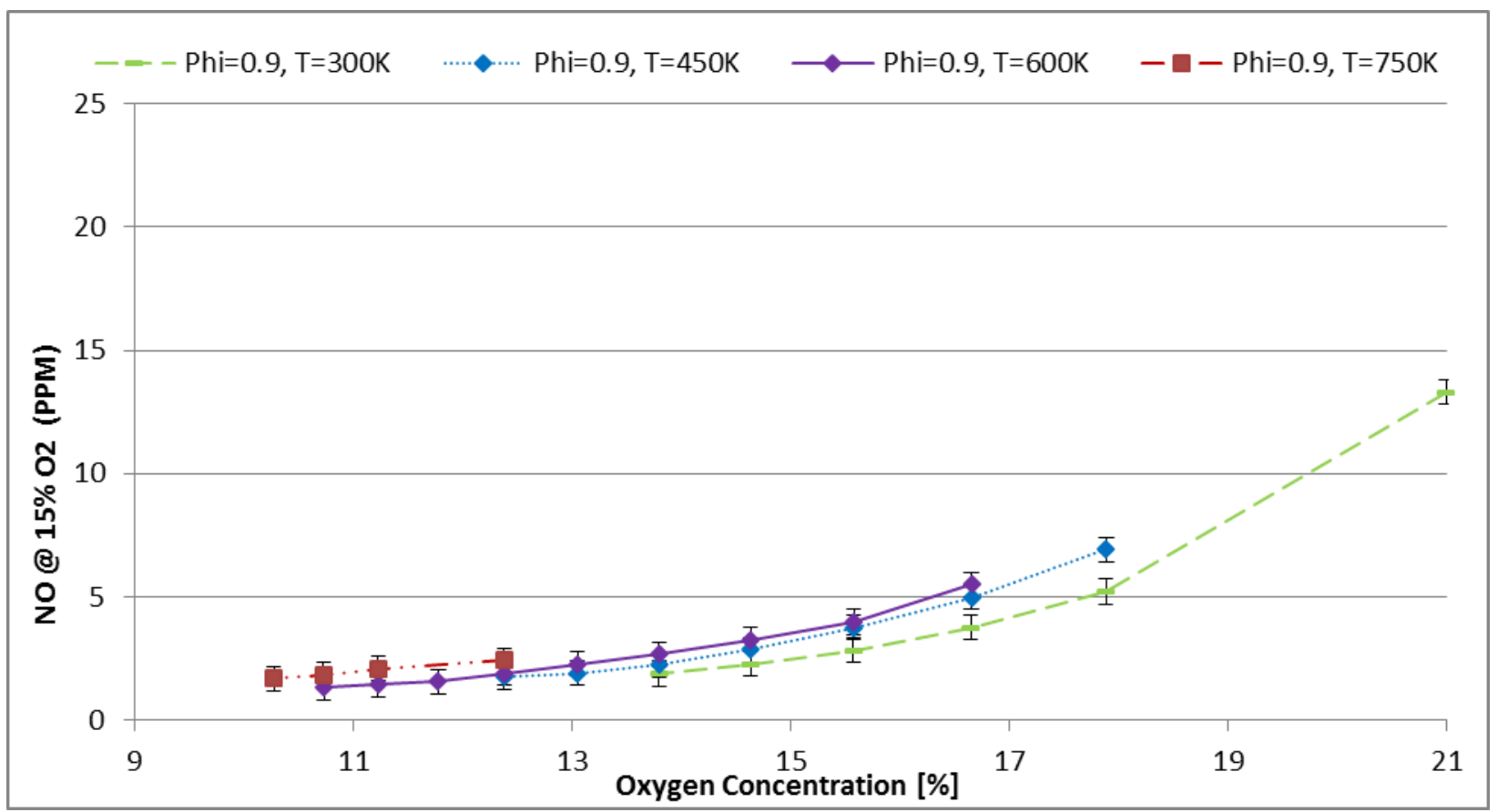

Figure 5. NO emissions for different oxygen concentration and diluents temperature using methane as a fuel 


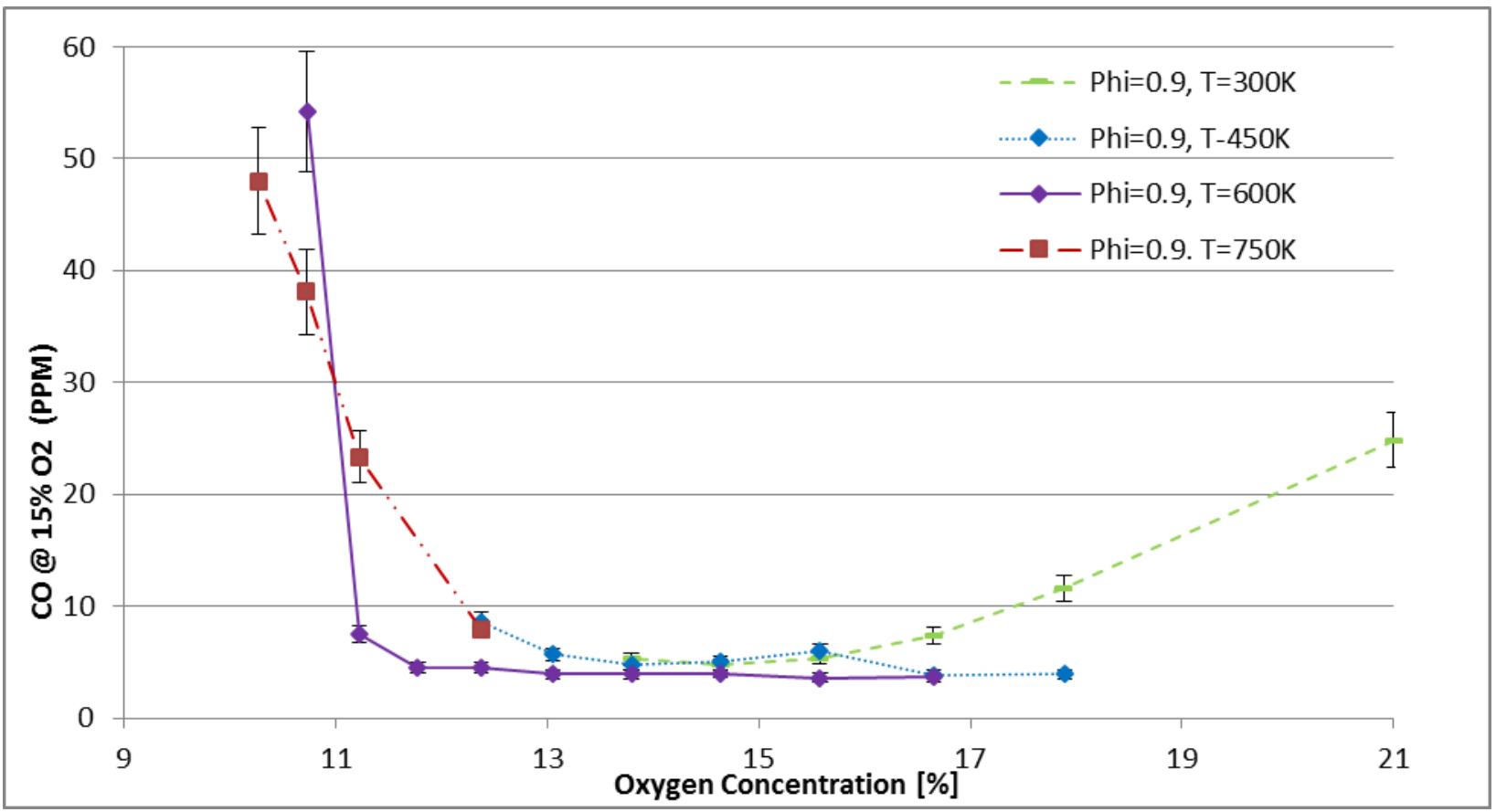

Figure 6. $\mathrm{CO}$ emissions for different oxygen concentration and diluents temperature using methane as a fuel 


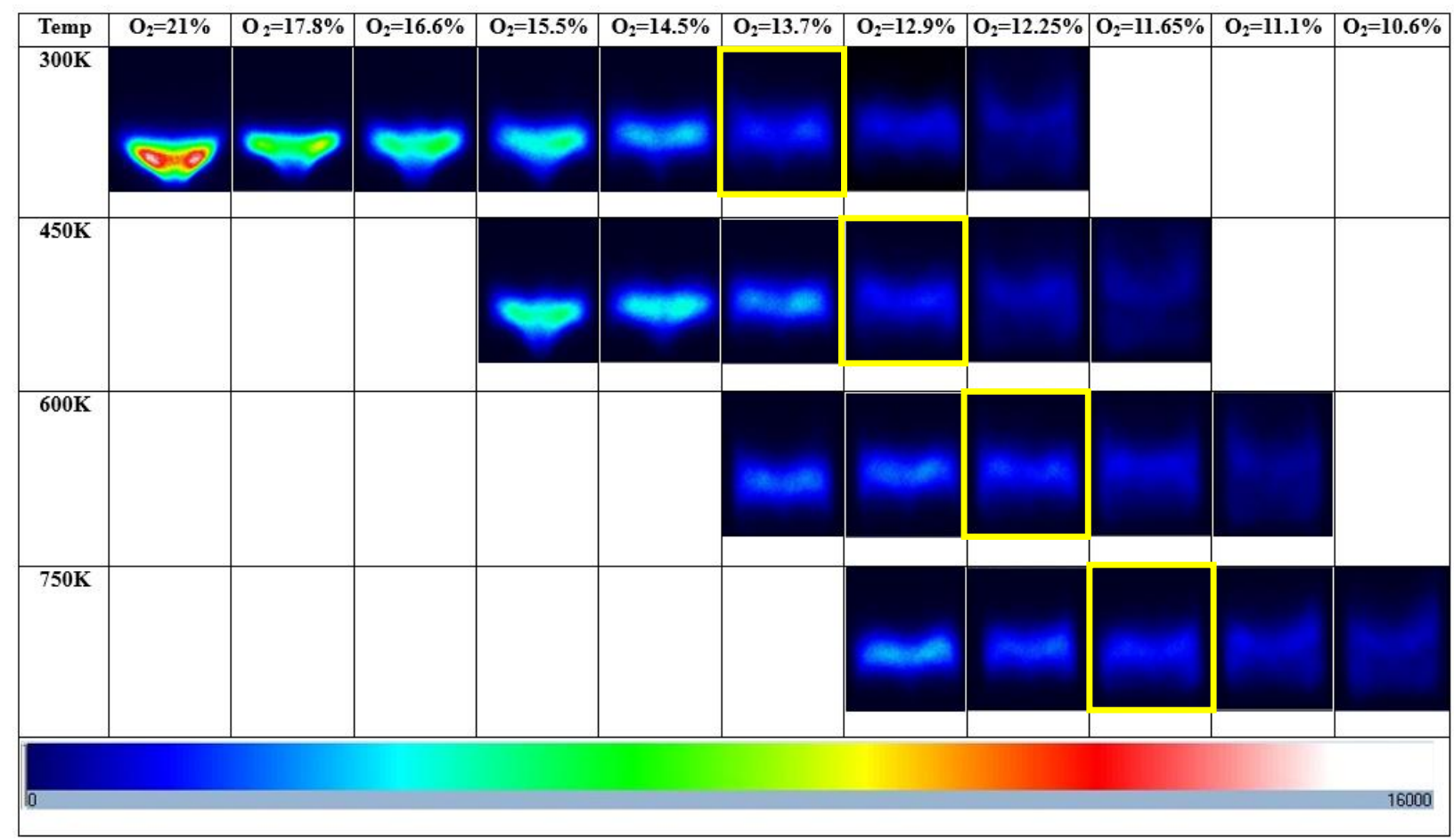

Figure 7. $\mathrm{OH}^{*}$ Chemiluminescence for the different oxygen concentrations in reactants at temperatures ranging from 300 to $750 \mathrm{~K}$ for propane 


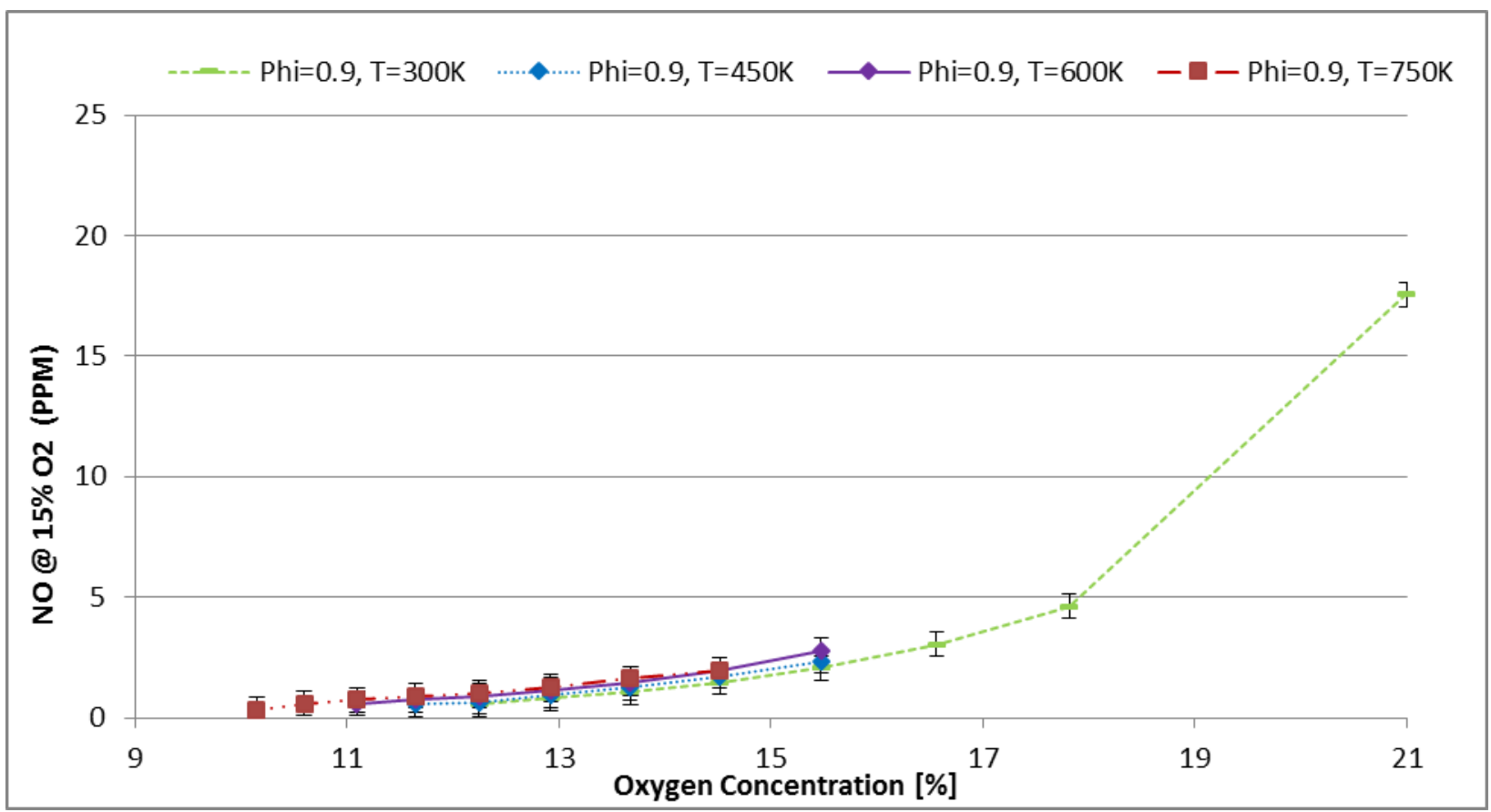

Figure 8. NO emissions for different oxygen concentration and diluents temperature using propane as a fuel 


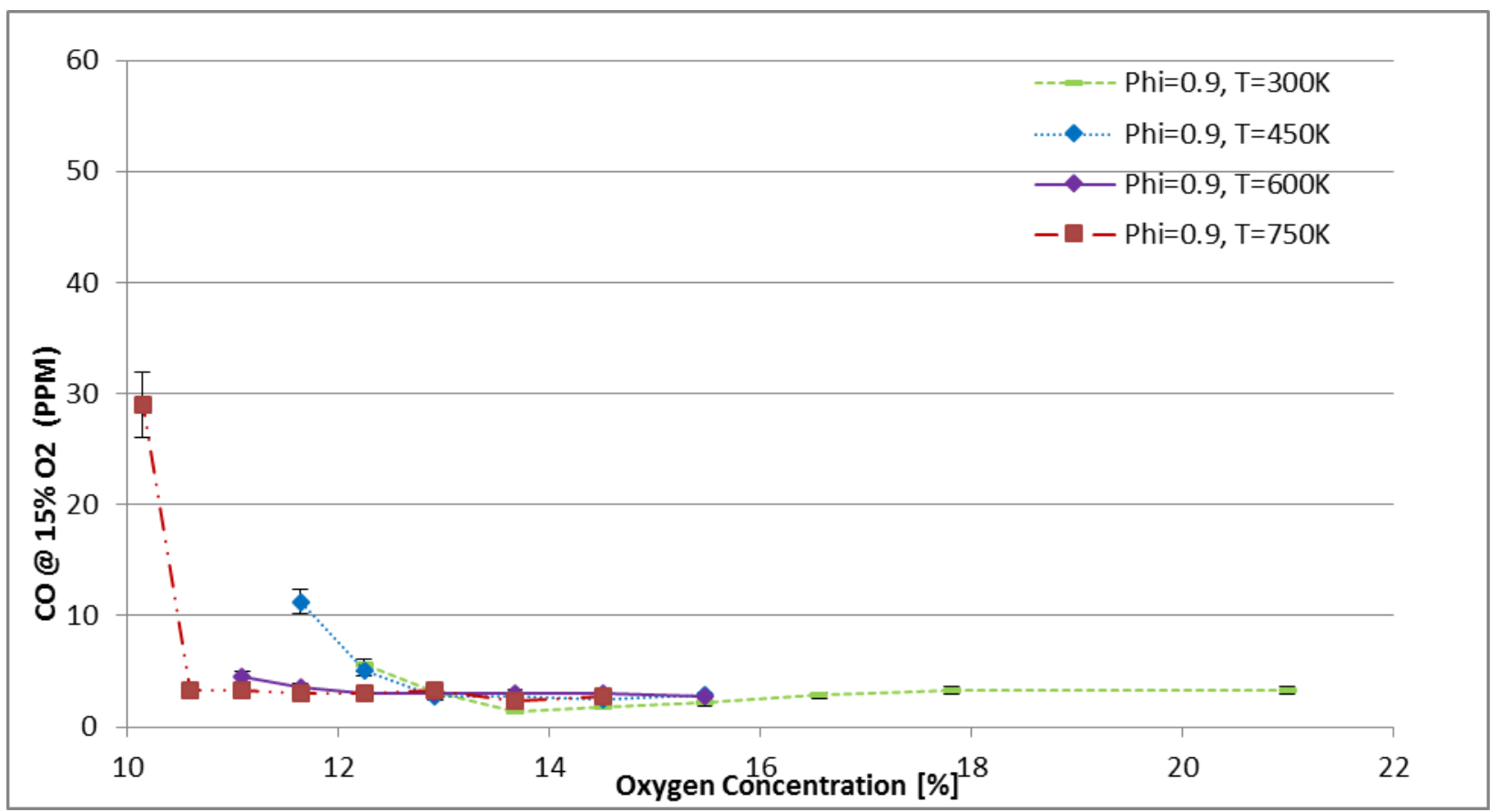

Figure 9. CO emissions for different oxygen concentration and diluents temperature using propane as a fuel 


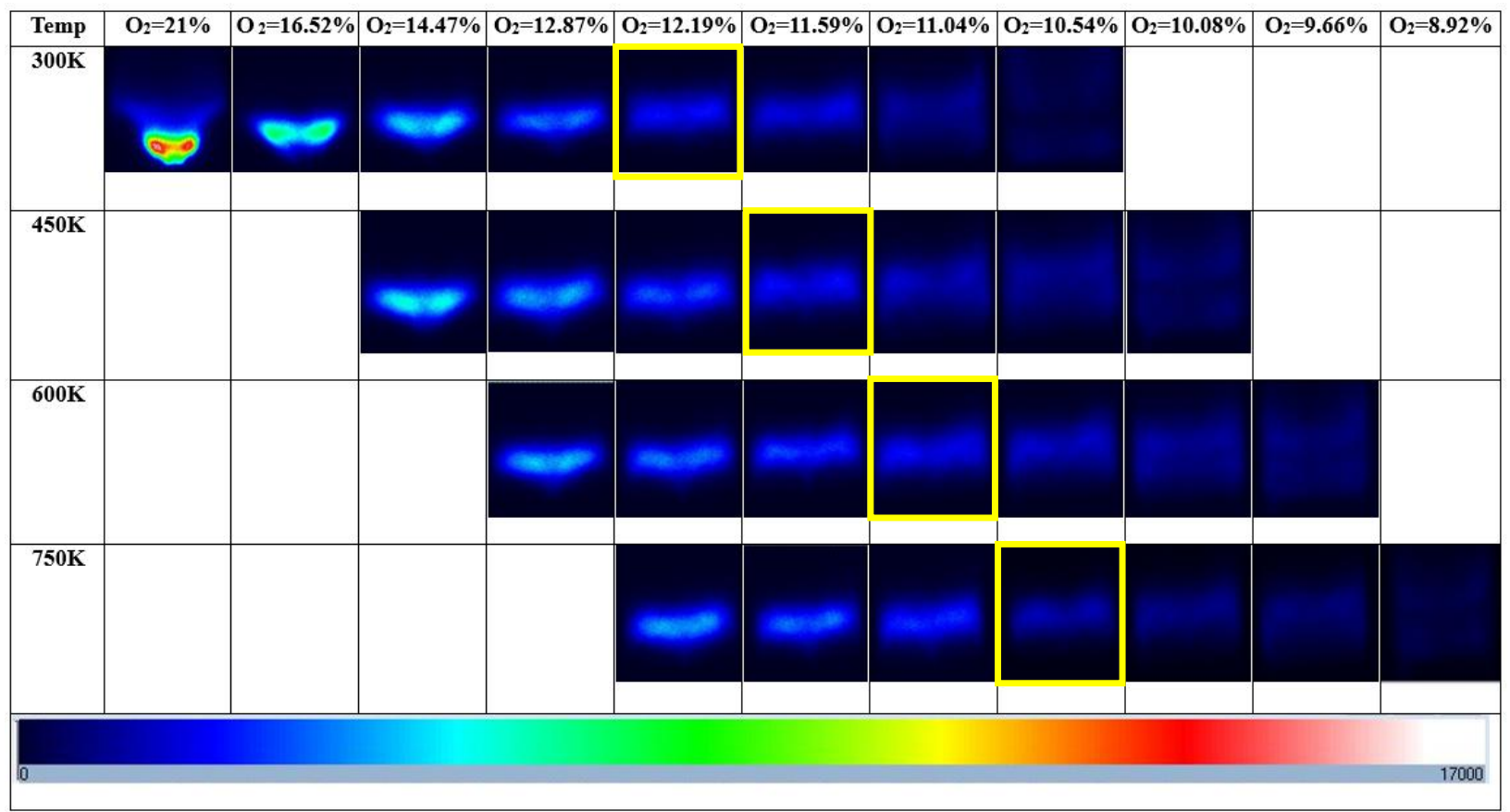

Figure 10. $\mathrm{OH}^{*}$ Chemiluminescence for the different oxygen concentrations in reactants at temperatures ranging from 300 to $750 \mathrm{~K}$ for hydrogen enriched methane 


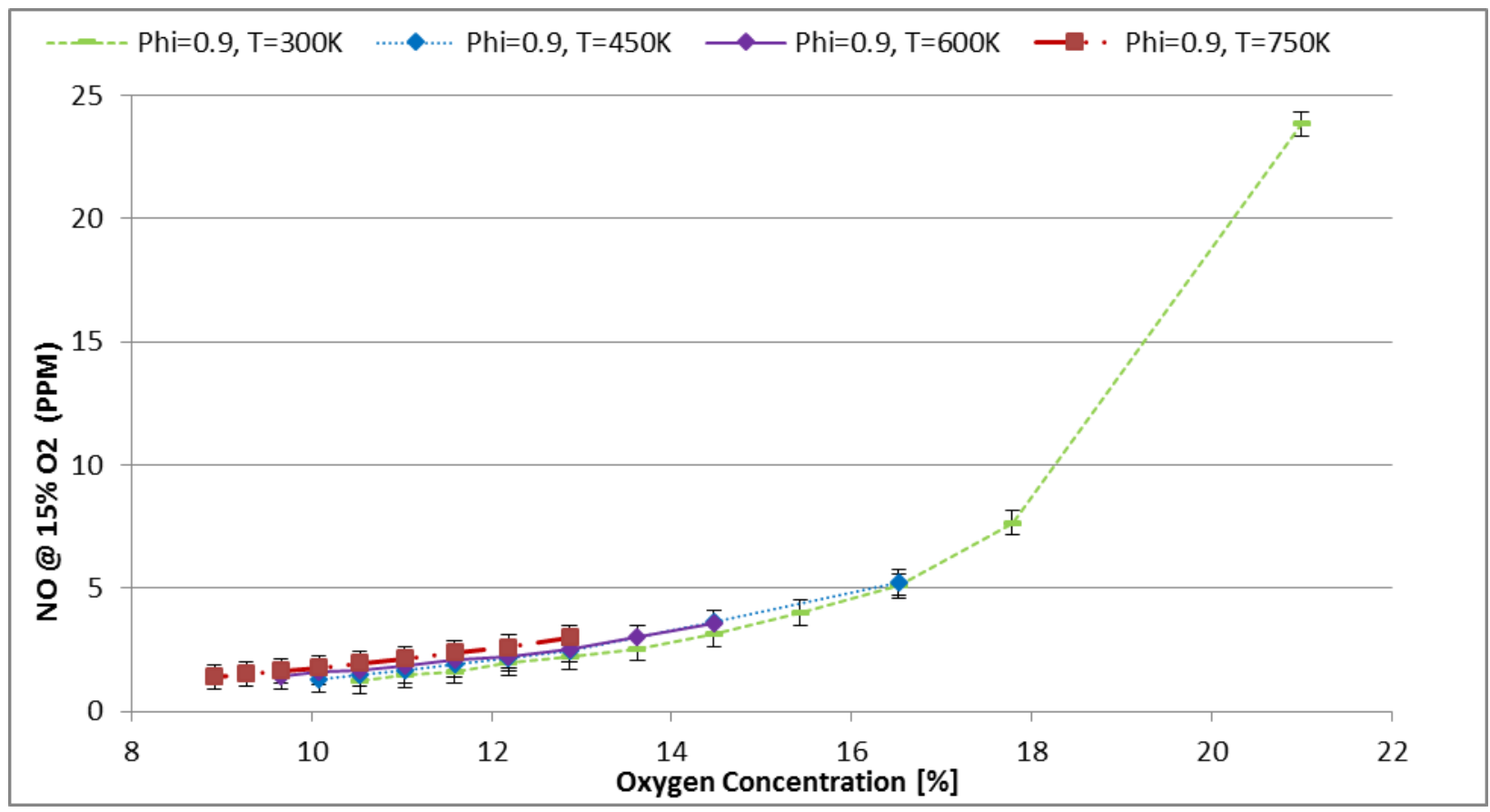

Figure 11. NO emissions for different oxygen concentration and diluents temperature using hydrogen enriched methane as a fuel 


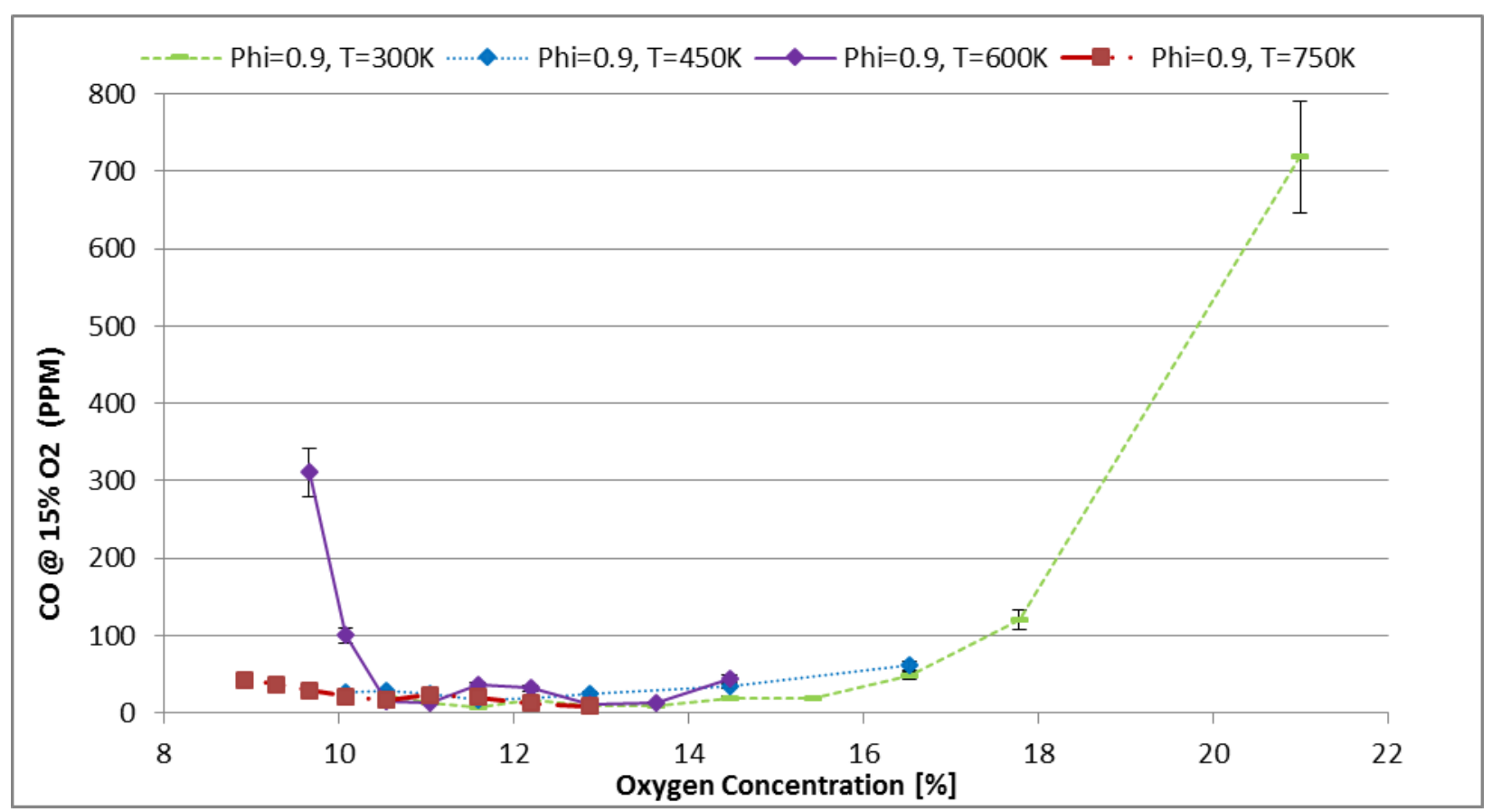

Figure 12. CO emissions for different oxygen concentration and diluents temperature using hydrogen enriched methane as a fuel 


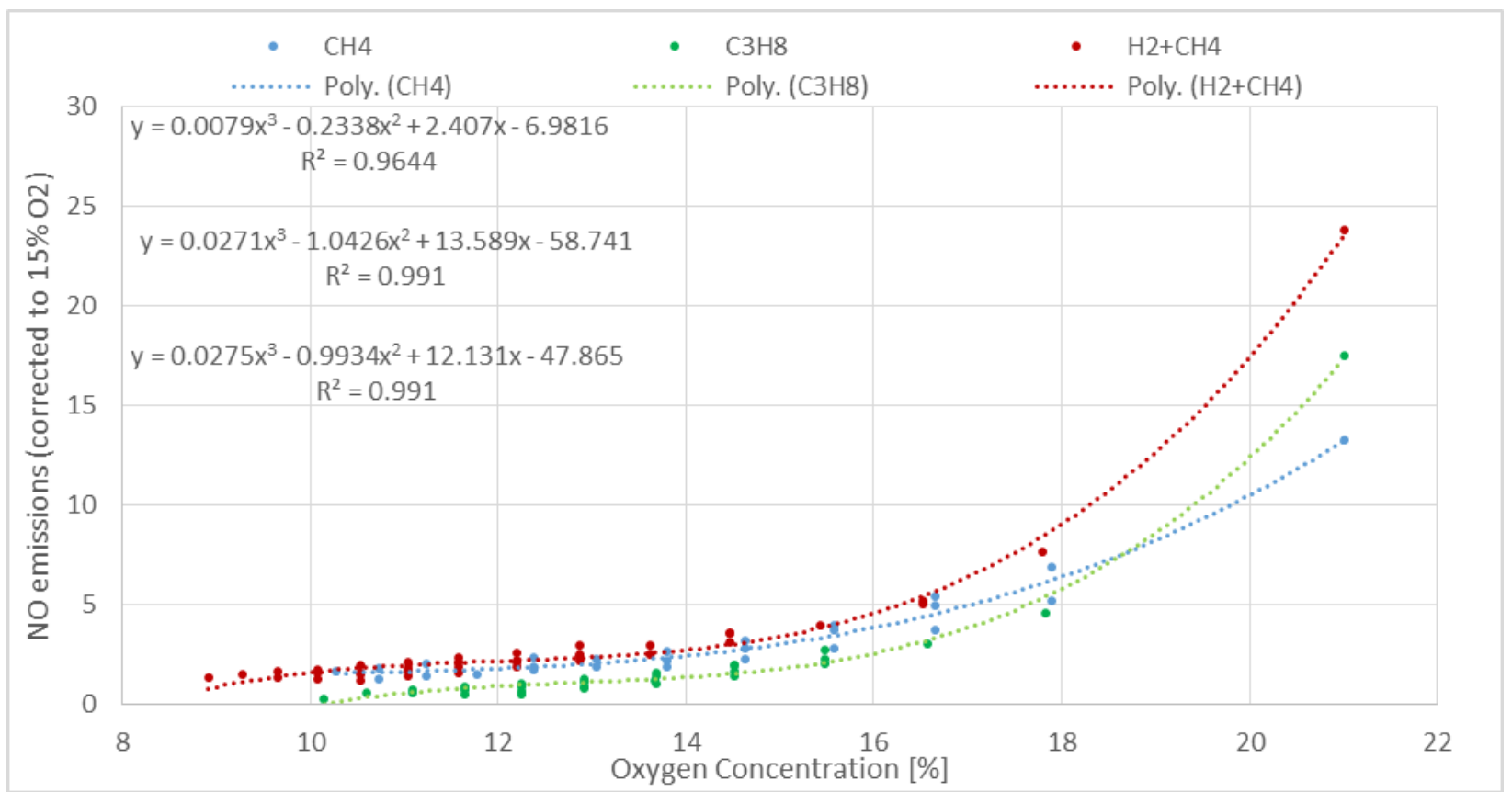

Figure 13. Change in in NO emission with oxygen concentration for the temperature range of $300 \mathrm{~K}-750 \mathrm{~K}$ using the different fuels examined at an equivalence ratio $=0.9$ 


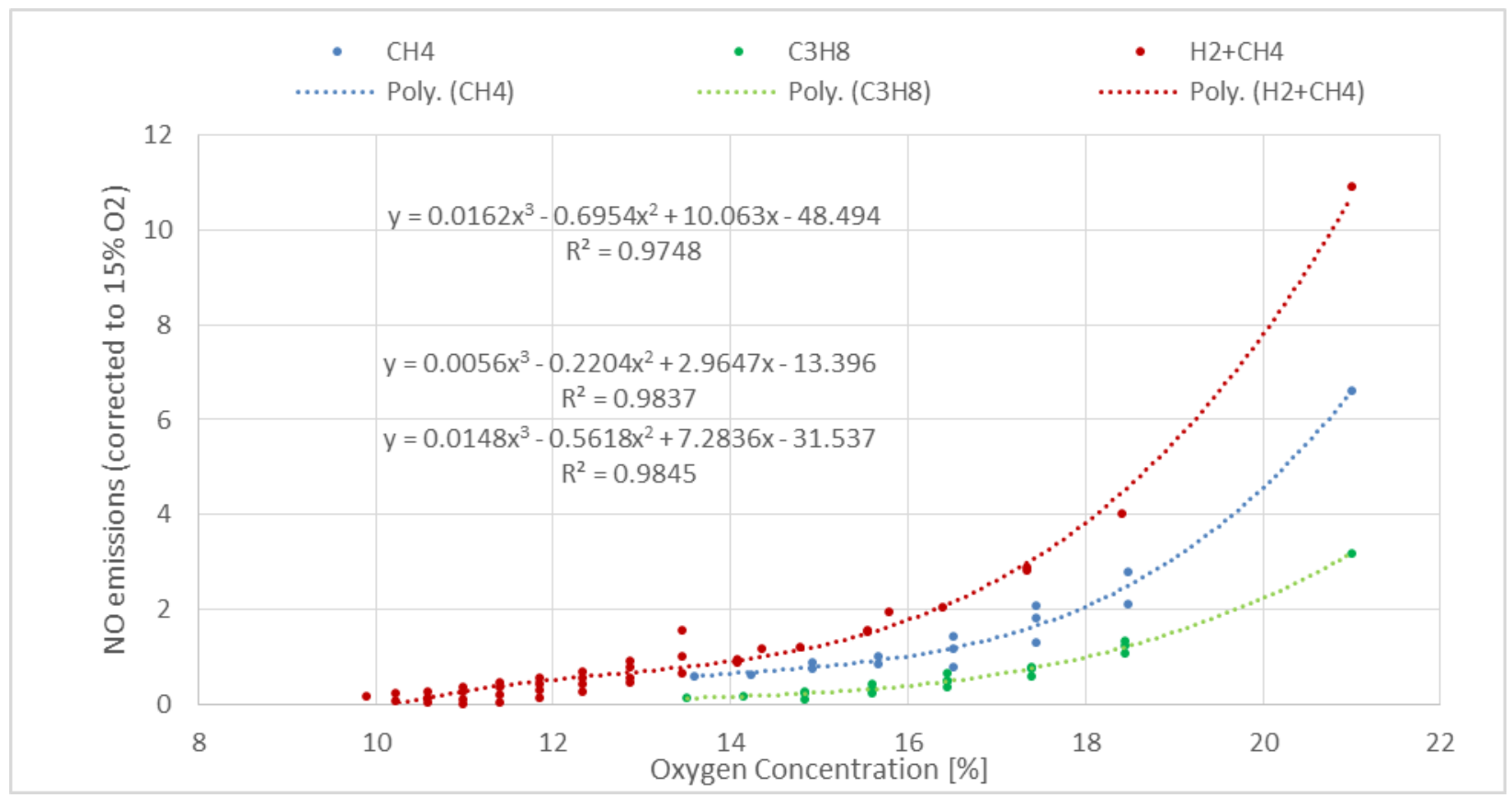

Figure 14. Change in in NO emission with oxygen concentration for the temperature range of $300 \mathrm{~K}-750 \mathrm{~K}$ using the different fuels examined at an equivalence ratio $=0.7$ 


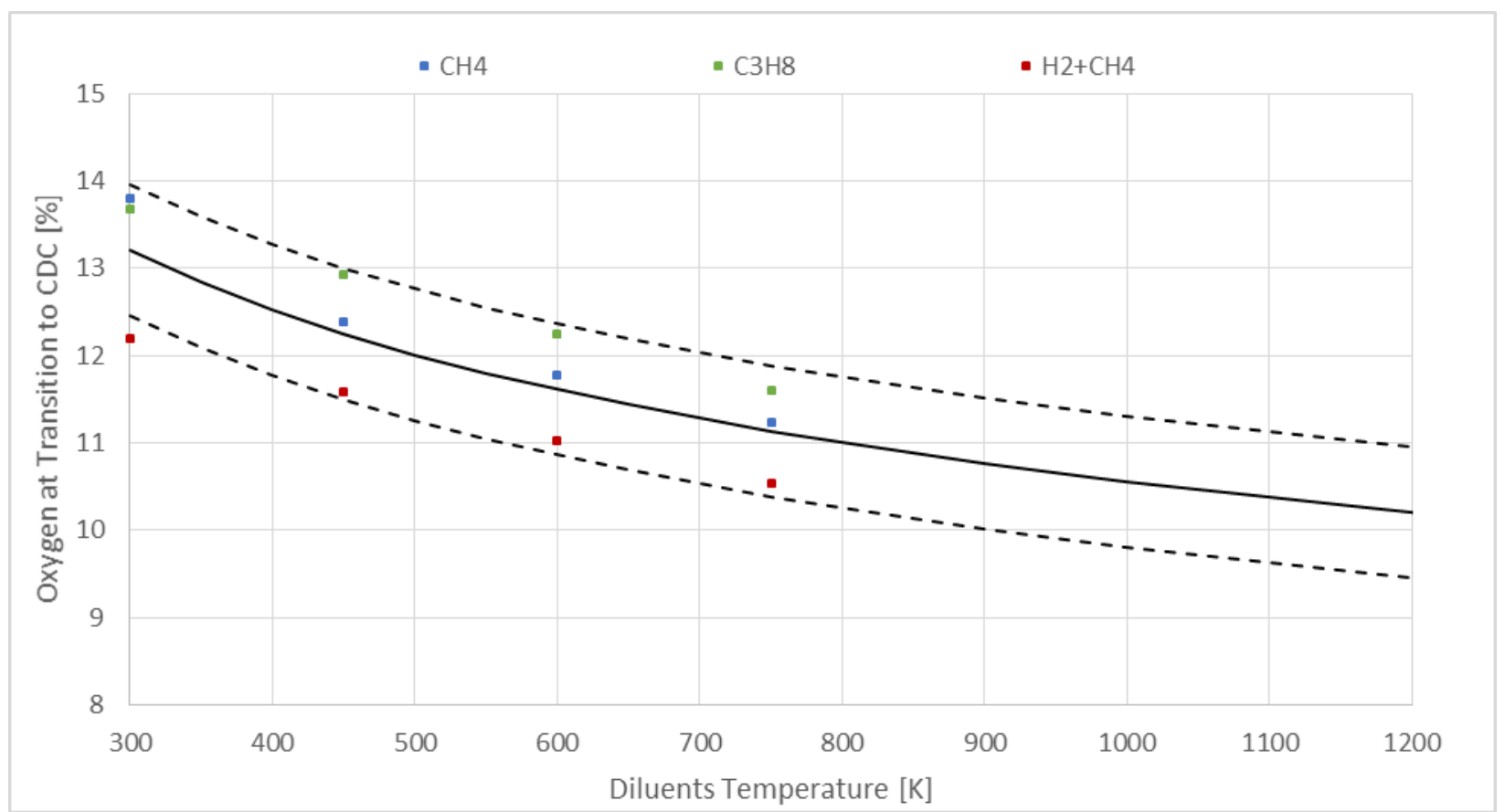

Figure 15. Oxygen concentration at transition to distributed combustion for different diluents temperature and fuels examined 